\title{
Does zinc concentration in the substrate influence the onset of flowering in Arabidopsis arenosa (Brassicaceae)?
}

\author{
Ewa Przedpelska-Wasowicz $\cdot$ Pawel Wasowicz
}

Received: 26 March 2012/Accepted: 1 September 2012/Published online: 11 September 2012

(C) The Author(s) 2012. This article is published with open access at Springerlink.com

\begin{abstract}
We investigated the impact of low zinc ( $\mathrm{Zn}$ ) concentrations in the substare on the onset of flowering in Arabidopsis arenosa (Brassicaceae). Experiments were carried out in controlled conditions using plants from four different populations. The research was aimed to verify experimentally the following hypotheses: (1) Zn content in the growth medium promote the onset of flowering in A. arenosa, (2) Changes in the onset of flowering induced by $\mathrm{Zn}$ depend on $\mathrm{Zn}$ concentration employed; (3) $\mathrm{Zn}$-induced early onset of flowering is an universal plant response present within the species and is not an effect of stress or physiological adaptation to high $\mathrm{Zn}$ content in the environment. Investigated plants were subjected to four different $\mathrm{Zn}$ concentrations: 0.4 (control), 155, 775 and $1,550 \mu \mathrm{M} \mathrm{Zn}^{2+}$. To asses stress level in investigated plants we calculated biomass accumulation and employed fluorometric methods. Zn content was estimated in shoots using atomic absorption spectroscopy. Differences in the onset of flowering were assessed using Kaplan-Meier curves. Our results showed that $\mathrm{Zn}$ was transported form growth medium to roots and shoots of investigated plants and that the content of $\mathrm{Zn}$ increased with the increase of $\mathrm{Zn}$ concentration in the growth medium. We evidenced that apart from one $\left(1,550 \mu \mathrm{M} \mathrm{Zn}{ }^{2+}\right)$ applied $\mathrm{Zn}$ concentrations did not caused stress in investigated plants what was
\end{abstract}

E. Przedpelska-Wasowicz $(\bowtie) \cdot$ P. Wasowicz

Department of Molecular Plant Physiology, Faculty of Biology, Institute of Botany, University of Warsaw, Miecznikowa 1, 02-096 Warszawa, Poland

e-mail: przedpelska@biol.uw.edu.pl

P. Wasowicz

Faculty of Biology and Environmental Sciences, Cardinal Stefan Wyszynski University in Warsaw, Wóycickiego 1/3,

01-938 Warszawa, Poland confirmed by two independent experimental approaches: measurement of biomass accumulation and chlorophyll $a$ fluorescence. Flowering curves obtained on the basis of calculation of Kaplan-Meier estimator showed that: (1) control plants originating from four different populations did not differ in terms of the onset of flowering, (2) plants from each population tested tends to enter flowering phase earlier in response to applied $\mathrm{Zn}$ concentrations than control plants, (3) plants treated with the lowest tested $\mathrm{Zn}$ concentration $\left(155 \mu \mathrm{M} \mathrm{Zn}{ }^{2+}\right)$ tend to flower earlier than plants treated with the higher concentration $(775 \mu \mathrm{M}$ $\mathrm{Zn}^{2+}$ ), (4) the impact of $\mathrm{Zn}$ on the onset of flowering did not depend on the origin on the plant material used (Zn-rich or $\mathrm{Zn}$-poor soils). Our results indicate that $\mathrm{Zn}$ ions present in the growth medium promote early flowering in A.aren$o s a$ and that this effect may depend on $\mathrm{Zn}$ concentration used. Zn-induced early flowering in A. arenosa seems to be an universal plant response present within the species and is not an effect of stress or physiological adaptation to high $\mathrm{Zn}$ content in the environment.

Keywords Arabidopsis arenosa Flowering - Zinc · Zinc accumulation

\section{Introduction}

Zinc is an important metallic element for both plant and animal life. The metal is relatively abundant as its mean concentration in the earth crust is estimated to $70 \mathrm{mg} / \mathrm{kg}$, ranging from 10 to $300 \mathrm{mg} / \mathrm{kg}$ (Malle 1992). There are, however, areas where low content of $\mathrm{Zn}$ in the soil, or its low bioavailability causes problems and impacts plant growth and human well-being (Cakmak et al. 1999; Ozturk et al. 2006). On the other hand in some areas $\mathrm{Zn}$ content in 
the substrate can significantly exceeds normal limits. Such areas are inhabited by $\mathrm{Zn}$-tolerant plants, well adopted to elevated content of the metal in the environment (Ernst 2006). Mechanisms of $\mathrm{Zn}$ tolerance in plants as well as problems connected with its deficit have been widely discussed in the literature in recent years (Cakmak et al. 1999; Cakmak 2008; Ernst 2006). In plant cells zinc is required by large number of proteins and is involved in many major metabolic processes by the presence in active sites of different enzymes (Mengel and Kirkby 2001; Kabata-Pendias 2010). It has been shown that zinc-containing molecules are also involved in the metabolism of nitrates and phosphates, RNA, proteins and carbohydrates (Mengel and Kirkby 2001; Nahed Abd El-Aziz and Balbaa 2007; Kabata-Pendias 2010). $\mathrm{Zn}$ is also essential in the synthesis of tryptophan, a precursor to IAA synthesis (Mengel and Kirkby 2001; Nahed Abd El-Aziz and Balbaa 2007). Zinc has been also confirmed to increase plant resistance to drought and disease (Kabata-Pendias 2010) and to be present in the protein being the product of CONSTANS gene involved in the regulation of flowering time (Putterill et al. 1995; Robson et al. 2001).

Taking into account an important role that zinc plays in major life processes in plants we were interested to see if it has also an impact on the onset of flowering. This question has never been raised before and the metal has never been considered as a factor influencing flowering time in plants.

Flowering time is an important character that enable plants to adapt to their local environments ( $\mathrm{Nah}$ and Chen 2010) and the onset of flowering is thought to be one of the key events in plant life cycle (Turnbull 2011) influencing most important plant characteristics as: seed set, interactions with pollinators and thus genetic variability (Neil and $\mathrm{Wu}$ 2006). It has been evidenced that plants adopt to changing environmental conditions such as seasonality of weather, day length (photoperiodism) and temperature (vernalization) as well as to environmental stress conditions by regulation of their flowering time (Brun et al. 2003; Nah and Chen 2010; Turnbull 2011). It has never been evidenced, however, that $\mathrm{Zn}$ content in the soil or in the growth medium can influence the onset of flowering. Taking into account that wild plants are able to grow on soils with dramatically different $\mathrm{Zn}$ content (Ernst 2006), it is also interesting to see whether the influence of $\mathrm{Zn}$ on the onset of flowering would be the same in both ecological groups: plants adapted to low and high $\mathrm{Zn}$ content in soil and thus showing two distinct physiological phenotypes. To accomplish this aim we needed a suitable model plant that is intraspecifically differentiated into two types of populations growing on $\mathrm{Zn}$-rich and $\mathrm{Zn}$-poor soils.

It seems that Arabidopsis arenosa (Brassicaceae) can serve as a good example of such species. It is common in central and northern part of Europe and closely related to
A. thaliana (estimated time of divergence between the two taxa is 5 Myr, Koch et al. 2000). A. arenosa can be considered as an ecologically unique within Arabidopsis due to the ability to inhabit wide range of different environments from natural habitats of grassy and sandy areas to disturbed habitats as roadsides, railroad tracks or waste heaps (Clauss and Koch 2006; Przedpelska and Wierzbicka 2007). One example of this ecological diversity is the ability of the species to grow in heavy-metal polluted sites as well as on soils free of these pollutants (Przedpelska and Wierzbicka 2007). Our previous research (Przedpelska and Wierzbicka 2007) showed that within A. arenosa exists two different types of populations: (1) growing on heavy metal polluted calamine soils rich in $\mathrm{Zn}$ (metallicolous populations, M) and (2) natural populations (non-metallicolous populations, $\mathrm{NM}$ ) growing on soil with normal $\mathrm{Zn}$ content.

During our previous studies on A. arenosa focused on $\mathrm{Zn}$ tolerance (Przedpelska and Wierzbicka 2007) we observed that tested plants showed similar response to low zinc concentrations used during tolerance tests carried out in uniform conditions. We noticed that the metal present in low concentration in the experimental growth medium induced early flowering in these plants. This observation could not be easily confirmed without setting out an experiment focused on the impact of low zinc content in the substrate on the onset of flowering in A. arenosa in controlled conditions.

As A. arenosa is a monocarpic plant, its flowering strategy could be expected to be a key element in its adaptation to changing environmental conditions. If this is true, populations from contrasting environments ( $\mathrm{M}$ vs. NM) should differ in the onset of flowering. It has been hypothesized that plants from Zn-enriched sites flower earlier and produce more seeds in order to increase survival in their harsh environment (Wierzbicka and Panufnik 1998; Zalecka and Wierzbicka 2002). This has never been tested experimentally.

We believe, that using A. arenosa as a model species creates unique opportunity to test possible $\mathrm{Zn}$ impact on the onset of flowering on two levels: (1) adaptive levelchanges in the onset of flowering time between populations from $\mathrm{Zn}$-rich soils and from natural soils (M vs. NM) that have developed during relatively long period of time as a result of adaptation to $\mathrm{Zn}$-enriched soils, (2) non-adaptive level-the impact of low (physiologically non-toxic) concentrations of $\mathrm{Zn}$ on the onset of flowering in A. arenosa plants regardless their origin; an universal response to $\mathrm{Zn}$ treatment in low concentrations present within the species.

In our study we employed $\mathrm{Zn}$ concentrations ranging from 0.4 to $1,550 \mu \mathrm{M} \mathrm{Zn}^{2+}$. The reader should bear in mind, however, that these concentrations cannot be simply compared with $\mathrm{Zn}$ content present in natural soils. The total content of $\mathrm{Zn}$ (usually measured and described in 
geochemical literature) is not a good indicator of bioavailable $\mathrm{Zn}$ resources present in the substrate. $\mathrm{Zn}$ bioavailability depends on many different factors such as: $\mathrm{pH}$, predominant chemical compound being a major $\mathrm{Zn}$ source, the content of organic matter in the soil etc. Cakmak et al. (1999) have shown that even in case of fairly high total $\mathrm{Zn}$ content in the soil (ranging from 40 to $80 \mathrm{mg} \mathrm{kg}^{-1}$ ) the concentration of bioavailable $\mathrm{Zn}$ can be about $0.25 \mathrm{mg} \mathrm{kg}^{-1}$, while widely accepted critical level of bioavailable $\mathrm{Zn}$ in soil for cultivated plants is $0.5 \mathrm{mg} \mathrm{kg}^{-1}$ (Cakmak et al. 1999). In case of our study it can be assumed that the amount of total and bioavailable $\mathrm{Zn}$ was almost the same. In light of this it can be stated that concentrations employed by us were within the limits of natural soils (with no $\mathrm{Zn}$ deficit) or higher, reaching the concentration of $1,550 \mu \mathrm{M}$ of bioavailable $\mathrm{Zn}^{2+}$ that has been found to be toxic for many wild and cultivated plant species (Kabata-Pendias 2010).

The present study was aimed to test the following hypotheses:

1. Zn content in the growth medium promote the onset of flowering in A. arenosa

2. Changes in the onset of flowering induced by $\mathrm{Zn}$ depend on $\mathrm{Zn}$ concentration employed

3. Zn-induced early onset of flowering is an universal plant response present within the species and is not an effect of stress or physiological adaptation to high $\mathrm{Zn}$ content in the environment

\section{Materials and methods}

\section{Plant material}

Seeds were sampled form four different populations inhabiting contrasting environments from calamine grassland and Zn-polluted sandy soils, through ruderal habitats of a railway line to relatively stable environment of forest edge. Seeds were sampled in bulk in July-August and subsequently used to grow plants used in experiments. Details on sampling locations were given in Table 1.

\section{Plant cultivation}

Seeds were germinated on artificial substrate (glass beads) in plastic trays using Knop's growth medium $(\mathrm{pH}=6)$ containing: $205,45 \mathrm{~g} / 1 \mathrm{Ca}\left(\mathrm{NO}_{3}\right)_{2} \cdot 4 \mathrm{H}_{2} \mathrm{O} ; 71,5 \mathrm{~g} / 1 \mathrm{KNO}_{3} ; 35,5$ $\mathrm{g} / \mathrm{K} \mathrm{KCl} ; 71,5 \mathrm{~g} / \mathrm{l} \mathrm{KH}_{2} \mathrm{PO}_{4} ; 145,42 \mathrm{~g} / 1 \mathrm{MgSO}_{4} \times 7 \mathrm{H}_{2} \mathrm{O}$, $28 \mathrm{~g} / \mathrm{l}$ EDTA-Fe and micronutrients according to Hoagland recipe modified by Bassalik (Strebeyko 1967). Seeds were germinated in light using growth chamber (Liebherr FKU 1800) at $24 \pm 1{ }^{\circ} \mathrm{C}$.
After germination plants were transferred to plastic pots containing perlite as a substrate and grown in semihydroponic conditions in greenhouse at $24 \pm 4{ }^{\circ} \mathrm{C}$, relative humidity of $45 \pm 5 \%$, light intensity of $\sim 120 \mu \mathrm{mol} / \mathrm{m}^{2} / \mathrm{s}$ and photoperiod of 16/8 h (light/dark).

At this stage we also started the treatment with different concentrations of zinc

1. $10 \mathrm{mg} / \mathrm{dm}^{3} \mathrm{Zn}^{2+}(155 \mu \mathrm{M})$ from $\mathrm{Zn}\left(\mathrm{NO}_{3}\right)_{2}$

2. $50 \mathrm{mg} / \mathrm{dm}^{3} \mathrm{Zn}^{2+}(775 \mu \mathrm{M})$ from $\mathrm{Zn}\left(\mathrm{NO}_{3}\right)_{2}$

3. $100 \mathrm{mg} / \mathrm{dm}^{3} \mathrm{Zn}^{2+}(1,550 \mu \mathrm{M})$ from $\mathrm{Zn}\left(\mathrm{NO}_{3}\right)_{2}$

4. control group (Knop's solution containing $0.4 \mu \mathrm{M}$ $\mathrm{Zn}^{2+}$ )

Zinc concentrations in the growth medium were established on the basis of pilot experiments in order to use both toxic and non-toxic concentrations. Concentrations

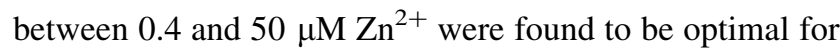
development of tested plants, whereas concentrations equal to $100 \mu \mathrm{M} \mathrm{Zn}{ }^{2+}$ and higher were toxic. There were 20 plants in each experimental unit, what gives a total of 320 tested plants (4 units and 4 populations tested).

In vivo chlorophyll fluorescence measurements

Measurements of chlorophyll $a$ fluorescence were carried out in order to determine plant reaction to applied $\mathrm{Zn}$ concentrations. Measurements were performed in vivo on plants from each experimental unit ( 5 plants tested per one unit). In total 80 plants were tested (4 populations and 4 experimental units). FMS-1 chlorophyll fluorometer (Hansatech Instruments) was employed. Fluorescence measurements were carried out on dark adapted leaves (30 min). Due to dark adaptation all light dependent reactions were inhibited. This resulted in complete re-oxidation of PSII electron acceptor molecules, opening PSII reaction centers and maximized the probability that absorbed light can be used for in photochemical reactions. After adaptation to darkness laves were illuminated with light of low intensity $\left(0.05 \mu \mathrm{mol} \mathrm{m} \mathrm{m}^{-2} \mathrm{~s}^{-1}\right)$. At this stage measurement of the fluorescence origin $\left(F_{o}\right)$ was done. Subsequently, leaves were exposed to an intense saturating pulse of light from the chlorophyll fluorometer $\left(4,500 \mu \mathrm{mol} \mathrm{m} \mathrm{m}^{-2} \mathrm{~s}^{-1}\right)$ and the maximum fluorescence yield $\left(F_{m}\right)$ was measured. On the basis of these measurements maximal photochemical efficiency $\left(\frac{F_{v}}{F_{m}}\right)$ of the photosystem II (PSII) in dark adapted leaves was calculated as $\frac{F_{v}}{F_{m}}=\frac{F_{m}-F_{o}}{F_{m}}$.

Biomass accumulation

After the end of experiment plants from each experimental unit were harvested, washed with deionized water and 
Table 1 Arabidopsis arenosa populations sampled in the present study

\begin{tabular}{|c|c|c|c|c|c|}
\hline \multirow{2}{*}{$\begin{array}{l}\text { Population } \\
\text { acronym }\end{array}$} & \multirow[t]{2}{*}{ Locality } & \multicolumn{2}{|c|}{ GPS coordinates } & \multirow{2}{*}{$\begin{array}{l}\text { Elevation } \\
\text { (m a.s.l.) }\end{array}$} & \multirow{2}{*}{$\begin{array}{l}\text { Edaphic } \\
\text { type }^{\mathrm{a}}\end{array}$} \\
\hline & & $\mathrm{N}$ & $\mathrm{E}$ & & \\
\hline BI & $\begin{array}{l}\text { Eastern Carpathians-Bieszczady Mts., Balnica, } \\
\text { railway line in forest }\end{array}$ & $49^{\circ} 11^{\prime} 08.4^{\prime \prime}$ & $22^{\circ} 12^{\prime} 52.9^{\prime \prime}$ & 696 & NM \\
\hline BO & $\begin{array}{l}\text { Bolesław near Olkusz (S Poland), calamine grassland developing } \\
\text { on } \mathrm{Zn}-\mathrm{Pb} \text { waste heap }\end{array}$ & $50^{\circ} 17^{\prime} 31.89^{\prime \prime}$ & $19^{\circ} 28^{\prime} 17.31^{\prime \prime}$ & 319 & M \\
\hline KA & Forest edge in Kampinoski National Park (Central Poland), sandy soil & $52^{\circ} 17^{\prime} 07.00^{\prime \prime}$ & $20^{\circ} 50^{\prime} 28.00^{\prime \prime}$ & 96 & NM \\
\hline MS & Miasteczko Śląskie (S Poland), surroundings of Zn smelter & $50^{\circ} 30^{\prime} 09.33^{\prime \prime}$ & $18^{\circ} 56^{\prime} 03.64^{\prime \prime}$ & 300 & M \\
\hline
\end{tabular}

${ }^{a}$ Edaphic type of each sampled population was established on the basis of heavy metal content in the substrate: $N M$ non-metallicolous population (substrate with natural, low content of $\mathrm{Zn}$ ), $M$ metallicolous populations (substrate with excessive content of $\mathrm{Zn}$ )

incubated in oven at $80{ }^{\circ} \mathrm{C}$ until constant weight and weighted using electronic scale. The biomass accumulation for control plants as well as for each treatment was expressed in grams as mean $\pm \mathrm{SD}$.

Observations of the onset of flowering

The onset of flowering was observed on 20 plants per each experimental unit. In total, the onset of flowering was recorded in 240 plants. Each day and at the same time flowering was assessed in experimental plants. The day in which first flower bud opened on a plant was treated as the onset of flowering.

\section{$\mathrm{Zn}$ concentration in leaves}

$\mathrm{Zn}$ content was assessed in leaves using plants treated with 10 and $50 \mathrm{mg} / \mathrm{kg} \mathrm{Zn}^{2+}$ as well as for control plants. Measurements were done using 3 plants per experimental unit. In total $\mathrm{Zn}$ content was measured in leaves from 36 plants using atomic absorption spectroscopy (AAS). Leaves were washed with demineralized water, dried and grounded prior to chemical analyses. Subsequently samples of $0.1 \mathrm{~g}$ of grounded leaves were treated with the mixture containing $\mathrm{HNO}_{3}$ (69\% solution) and $\mathrm{H}_{2} \mathrm{O}_{2}(30 \%$ solution), 9:1 (v/v), in Teflon bombs. Certified plant reference material was used as a control sample. In order to test purity of chemicals used in the process pure mixture of $\mathrm{HNO}_{3}$ and $\mathrm{H}_{2} \mathrm{O}_{2}$ (without any plant material) was used as a reference sample. Zinc content was then measured by flame AAS using Solar M6 spectrometer (Thermo Scientific) and expressed in $\mathrm{mg} / \mathrm{kg}$ of dry weight.

\section{Statistical analyses}

\section{Kaplan-Meier estimator}

To explore differences between experimental groups regarding the onset of flowering we used Kaplan-Meier estimator (Kaplan and Meier 1958). The analytical technique is most widely used in medical sciences and is particularly useful when researcher has to cope with censored observations (Kirkwood and Sterne 2003). Censored observations arise always when the variable of interest represent the time to a terminal event (in our case the onset of flowering), and when duration of the study have to be limited in time. We estimated survival function directly from continuous survival times (Kaplan and Meyer 1958):

$\hat{S}_{(t)}=\prod j: t_{j} \leq t\left[1-\frac{d_{j}}{n_{j}}\right]$

where: $\hat{\mathrm{S}}_{(\mathrm{t})}$-represents estimated survival probability at time t: $\mathrm{P}(\mathrm{T}>\mathrm{t}), \prod j: t_{j} \leq t$-multiply the probability of surviving event time $t$ with the probabilities of surviving all the previous event times, $d_{j}$-is the number of deaths up to point $\mathrm{t}, n_{j}$-is number of individuals at risk just prior to $\mathrm{t}$, $1-\frac{d_{j}}{n_{j}}$-proportion surviving the event time t.

In case of our research survival time was defined as the number of days from the beginning of the experiment (seeds sowing) to the onset of flowering in each individual plant and corresponding Kaplan-Meier curve (here called "flowering curve") depicts the probability of "no-flowering" at the time t. To assess statistical significance between experimental units log-rank, F-Cox and Cox-Mantel tests were used $(\alpha=0.05)$.

ANOVA and post hoc tests

Differences in $\mathrm{Zn}$ content in shoots were assessed using oneway ANOVA and post hoc Tukey's HSD test $(\alpha=0.05)$. All the statistical analyses were carried out using Statistica 9.1 software package (Statsoft Inc., USA).

\section{Results}

Zn content in plants

Our results showed that increased content of $\mathrm{Zn}$ in the growth medium caused increased content of the metal in shoots (Fig. 1). 
Mean $\mathrm{Zn}$ concentration in control plants was 31.88 $\mathrm{mg} / \mathrm{kg} \mathrm{Zn}$ in D.W. (Fig. 1). In experimental groups treated with increasing $\mathrm{Zn}$ concentration (155 and $775 \mu \mathrm{M} \mathrm{Zn^{2+ }}$ ) mean $\mathrm{Zn}$ content was 82.40 and $239.84 \mathrm{mg} / \mathrm{kg} \mathrm{Zn}$ in D.W., for lower and higher $\mathrm{Zn}$ concentration respectively (Fig. 1).

Stress level in investigated plants

Table 2 shows mean values of $\frac{F_{v}}{F_{m}}$ ratio measured in investigated plants for all the experimental units. Values of $\frac{F_{v}}{F_{m}}$ ratio obtained for control plants varied narrowly between 0.83 and 0.84 , what indicate that control plants were in good physiological state, showing no signs of stress. Similar results were obtained for two lower zinc concentrations (155 and $775 \mu \mathrm{M}$ $\mathrm{Zn}^{2+}$ ). We noticed that plants from BI population treated with $775 \mu \mathrm{M} \mathrm{Zn}^{2+}$ showed slightly lower $(0.78)$ mean value of the $\frac{F_{v}}{F_{m}}$ ratio. Table 2 shows that value of $\frac{F_{v}}{F_{m}}$ ratio decreased substantially in population KA. Plants from BI population subjected to the highest concentration of $\mathrm{Zn}\left(1,550 \mu \mathrm{MZn}^{2+}\right)$ showed signs of acute toxicity: substantially decreased biomass production, numerous chloroses and substantially smaller size, when compared with plants from BO and MS populations. Small size of leaves made impossible measurement of $\frac{F_{v}}{F_{m}}$ ratio for this experimental unit.

Table 3 presents mean biomass accumulation in investigated plants. Substantial differences in plant biomass (assessed as dry weight) between investigated populations was recorded. Significant decrease in mean dry weight of investigated plants was recorded for population $\mathrm{BI}$ and $\mathrm{KA}$ in case of the highest $\mathrm{Zn}$ concentration $\left(1,550 \mu \mathrm{M} \mathrm{Zn}{ }^{2+}\right)$. In case of remaining populations (BO and MS) accumulated biomass was the highest in plants subjected to high $\mathrm{Zn}$ concentrations.

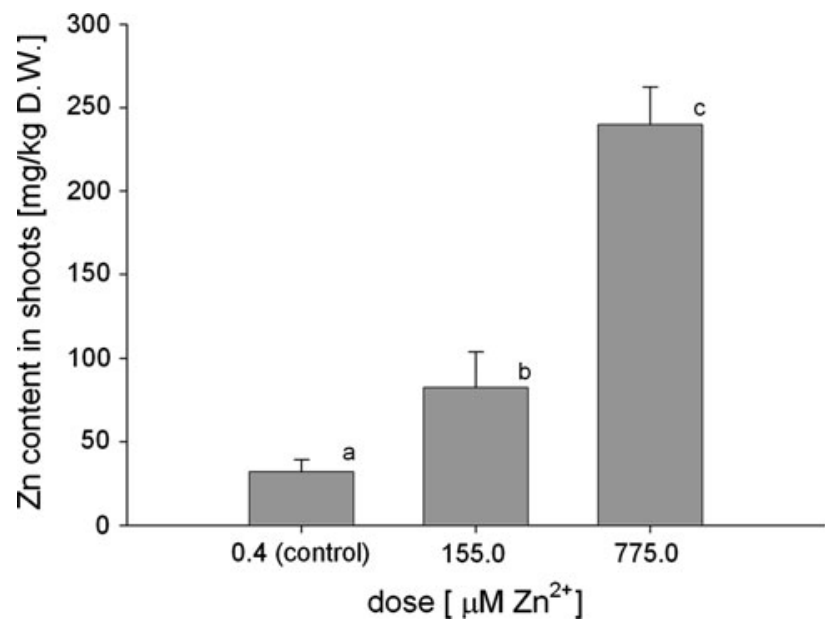

Fig. $1 \mathrm{Zn}$ content in A. arenosa plants treated with different $\mathrm{Zn}$ concentrations $\left(0.4,155\right.$ and $\left.775 \mu \mathrm{M} \mathrm{Zn}^{2+}\right)$. Estimated using atomic absorption spectroscopy
The onset of flowering

Figure 2 shows flowering curves obtained for control plants originating from populations inhabiting contrasting environments: metalliferous (Zn-rich) and non-metalliferous soils (showing natural, low content of $\mathrm{Zn}$ ). Significance tests evidenced that there is no differences in the onset of flowering between plants from $\mathrm{M}$ and $\mathrm{NM}$ populations in A. arenosa $(p \gg 0.05)$.

Using Kaplan-Meier estimator we studied the effect of zinc concentration on the onset of flowering on population level. Figure 3a-d shows flowering curves obtained for each investigated population. We employed three tests (log-rank test, F-Cox test and Cox-Mantel test) in order to assess statistical significance of our observations. Our results evidenced that plants treated with the lowest concentration of $\mathrm{Zn}\left(155 \mu \mathrm{M} \mathrm{Zn}^{2+}\right)$ flowered earlier than control plants regardless the population studied ( $\mathrm{M}$ vs. NM). Statistical significance of these differences was confirmed by three different tests (see above) at the significance level of $\alpha=0.05$. Plants treated with $775 \mu \mathrm{M}$ $\mathrm{Zn}^{2+}$ also showed a tendency to flower earlier than control plants (Fig. 3a-d). These differences, however, were significant only in populations BO (Fig. 3d) and KA (Fig. 3a, $\alpha=0.05$ ).

We investigated also the impact of zinc concentration on flowering using data from overall sample (all individuals and all populations). Results of this analysis were shown in Fig. 4. We evidenced that differences between control plants and both Zn-treated groups were statistically significant. Concordant results $(p<0.05)$ were obtained in case of all three tests. Analysis carried out on overall sample evidenced also that plants treated with lower $\mathrm{Zn}$ concentration flowered earlier than those treated with higher concentration of $\mathrm{Zn}(p<0.05$, concordant results for three tests employed).

We also compared flowering time in reaction to applied $\mathrm{Zn}$ concentration between populations growing on metalliferous (Zn-rich) and non-metalliferous soils (natural, low content of $\mathrm{Zn})$. No significant $(\alpha=0.05)$ differences in flowering time between $\mathrm{M}$ and NM populations within the species were detectable in response to different $\mathrm{Zn}$ concentrations (Fig. 5).

\section{Discussion}

Zinc content in plants

In order to test whether $\mathrm{Zn}$ from the growth medium was effectively transported to plants and whether changes in the content of the metal in the growth medium influenced $\mathrm{Zn}$ 
Table 2 Maximal photochemical efficiency $\left(\frac{F_{v}}{F_{m}}\right)$ of the photosystem II (PSII) in dark adapted leaves of A. arenosa subjected to different concentrations of $\mathrm{Zn}$

\begin{tabular}{|c|c|c|c|c|c|c|c|c|c|}
\hline & \multirow[t]{2}{*}{ Zn concentration $(\mu \mathrm{M})$} & \multicolumn{2}{|c|}{0.4 (control) } & \multicolumn{2}{|l|}{155} & \multicolumn{2}{|l|}{775} & \multicolumn{2}{|l|}{1,550} \\
\hline & & Mean & SD & Mean & SD & Mean & SD & Mean & SD \\
\hline \multirow[t]{4}{*}{ Population acronym } & $\mathrm{BI}$ & 0.84 & 0.007 & 0.83 & 0.006 & 0.78 & 0.032 & - & - \\
\hline & $\mathrm{BO}$ & 0.84 & 0.008 & 0.83 & 0.015 & 0.85 & 0.004 & 0.82 & 0.023 \\
\hline & KA & 0.83 & 0.012 & 0.82 & 0.016 & 0.83 & 0.010 & 0.49 & 0.141 \\
\hline & MS & 0.84 & 0.006 & 0.83 & 0.016 & 0.85 & 0.005 & 0.80 & 0.024 \\
\hline
\end{tabular}

Table 3 Mean biomass accumulation in investigated plants subjected to different concentrations of $\mathrm{Zn}$

\begin{tabular}{|c|c|c|c|c|c|c|c|c|c|}
\hline & \multirow{2}{*}{$\begin{array}{l}\text { Zn concentration }(\mu \mathrm{M}) \\
\text { Dry weight }(\mathrm{g})\end{array}$} & \multicolumn{2}{|c|}{0.4 (control) } & \multicolumn{2}{|l|}{155} & \multicolumn{2}{|l|}{775} & \multicolumn{2}{|l|}{1,550} \\
\hline & & Mean & SD & Mean & SD & Mean & SD & Mean & SD \\
\hline \multirow[t]{4}{*}{ Population acronym } & $\mathrm{BI}$ & 1.09 & 0.19 & 0.90 & 0.12 & 0.86 & 0.17 & 0.03 & 0.01 \\
\hline & $\mathrm{BO}$ & 0.24 & 0.07 & 0.31 & 0.12 & 0.63 & 0.18 & 0.51 & 0.10 \\
\hline & KA & 0.67 & 0.15 & 0.60 & 0.29 & 0.53 & 0.20 & 0.25 & 0.13 \\
\hline & MS & 0.94 & 0.31 & 1.08 & 0.33 & 1.55 & 0.67 & 1.71 & 0.49 \\
\hline
\end{tabular}

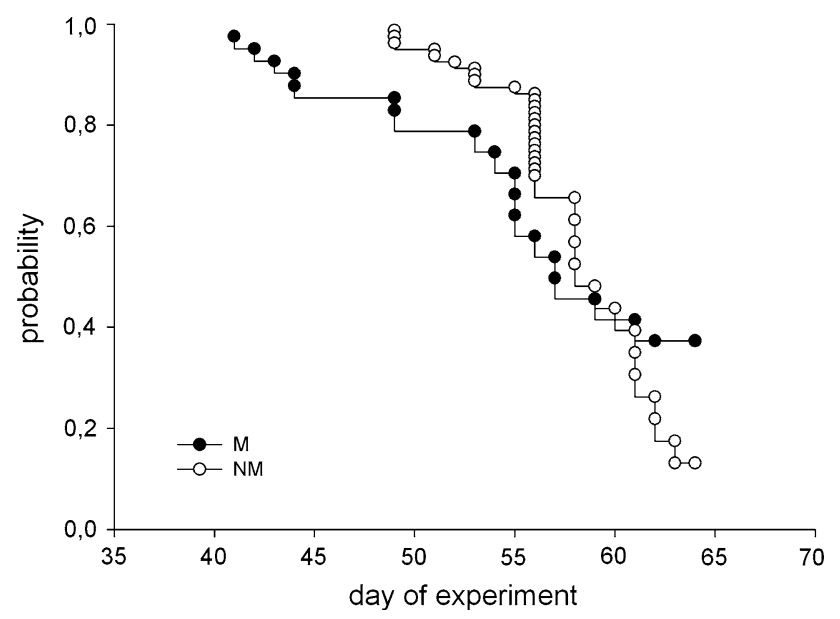

Fig. 2 Kaplan-Meier curves showing predicted probability of "no flowering" in plants grown in control conditions $\left(0.4 \mu \mathrm{M} \mathrm{Zn}^{2+}\right)$ and originating from $A$. arenosa populations belonging to two edaphic types: metallicolous-Zn-rich (M) versus non-metallicolous-Znpoor (NM)

content in plants we carried out chemical analysis using AAS technique. This approach enabled us to verify experimentally $\mathrm{Zn}$ content in plants subjected to different $\mathrm{Zn}$ concentrations in the growth medium. We found that $\mathrm{Zn}$ concentrations measured by us in investigated plants were within physiological limits and were significantly lower than toxic level of the element reported for plants (KabataPendias 2010).
Stress level in investigated plants

Many authors pointed out that stress can have substantial effect on early flowering (Roux et al. 2006; Wada and Takeno 2010; Yaish et al. 2011). In order to exclude Zn induced stress as a cause of the changes in the onset of flowering we examined stress level in A. arenosa.

The ratio of $\frac{F_{v}}{F_{m}}$ is widely used as a screening in vivo parameter for stress response in plants (Schreiber et al. 1994; Andrews et al. 1995; Waldhoff et al. 2002; Mallick and Mohn 2003). It has been show that in vivo fluorescence measurements are reliable and fast method used for assessing changes in photosynthetic activity in leaves induced by stress factors, both of natural and anthropogenic origin. Therefore we decided to use $\frac{F_{v}}{F_{m}}$ ratio as an indicator of stress caused by zinc ions.

It seems, that both $\mathrm{Zn}$ concentrations were well-tolerated and did not cause stress in investigated plants. It is widely accepted that the values of $\frac{F_{v}}{F_{m}}$ ratio ranging from 0.79 to 0.84 are optimal and were confirmed in different plant species (Maxwell and Johnson 2000; Kitajima and Butler 1975). Lower values, however, are indicator of stress (Maxwell and Johnson 2000; Kitajima and Butler 1975). We noticed that plants from BI population treated

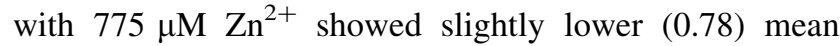
value of the $\frac{F_{v}}{F_{m}}$ ratio. This decrease was, however, minimal and negligible when taking into account the value of standard deviation. Situation was quite different in case of the highest $\mathrm{Zn}$ concentration. 

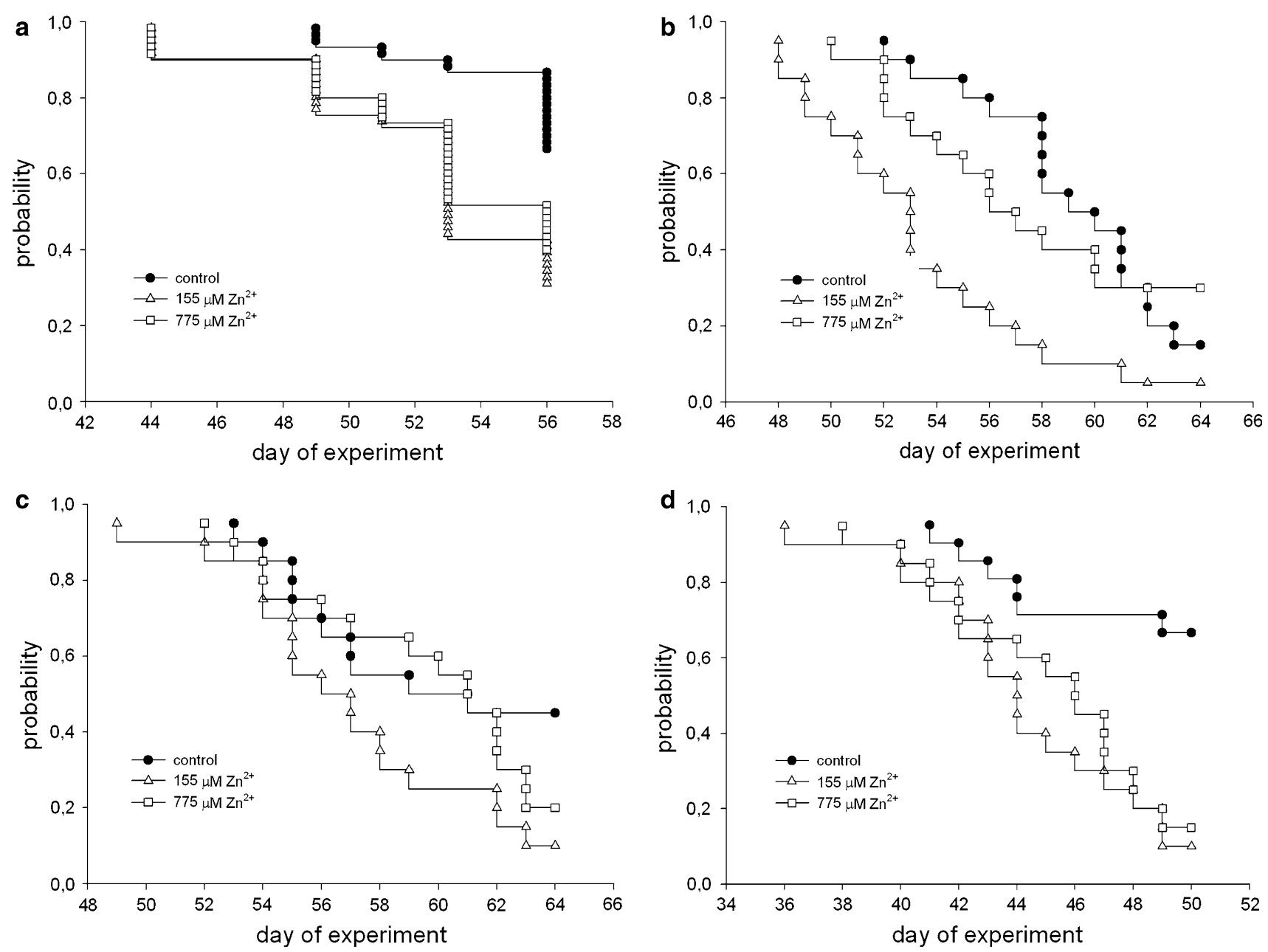

Fig. 3 Kaplan-Meier curves showing predicted probability of "no flowering" in plants from different populations of $A$. arenosa grown in control conditions $\left(0.4 \mu \mathrm{M} \mathrm{Zn}^{2+}\right)$ and treated with different $\mathrm{Zn}$

concentrations (155 and $775 \mu \mathrm{M} \mathrm{Zn}^{2+}$ ). a population $\mathrm{KA}$, b population $\mathrm{BI}, \mathbf{c}$ population MS, $\mathbf{d}$ population $\mathrm{BO}$

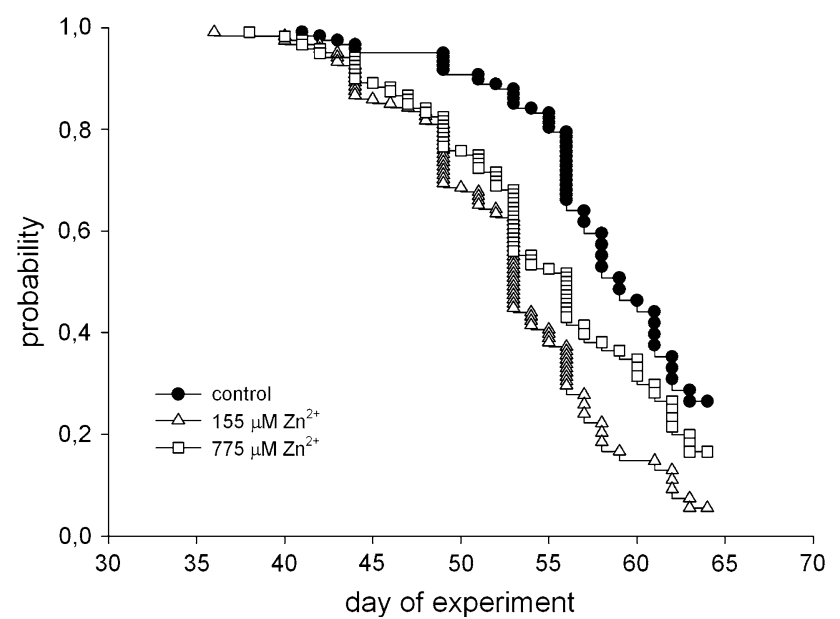

Fig. 4 Kaplan-Meier curves showing predicted probability of "no flowering" in overall sample of plants from different populations of A. arenosa grown in control conditions $\left(0.4 \mu \mathrm{M} \mathrm{Zn}^{2+}\right)$ and treated with different $\mathrm{Zn}$ concentrations (155 and $775 \mu \mathrm{M} \mathrm{Zn}^{2+}$ )
We investigated also biomass accumulation in investigated plants. Results of these analyses were in agreement with data from in vivo fluorescence measurements and confirmed that only the highest concentration of $\mathrm{Zn}$ caused significant decrease in biomass accumulation observed in two populations (BI and KA).

Data obtained from these experiments show clearly that control plants as well as plants treated with two lower zinc concentrations were in good physiological state, showing no signs of stress caused by applied $\mathrm{Zn}$ concentrations. It seems that these concentrations, although higher than found in most of natural environments (Kabata-Pendias 2010), are within tolerance limits for A. arenosa. Plants treated with the highest $\mathrm{Zn}$ concentration, showing clear signs of toxicity and stress, were excluded from further experiments in order to minimize the possibility that observed differences in flowering could be attributed to stress-related factors. It seems therefore, that in our 

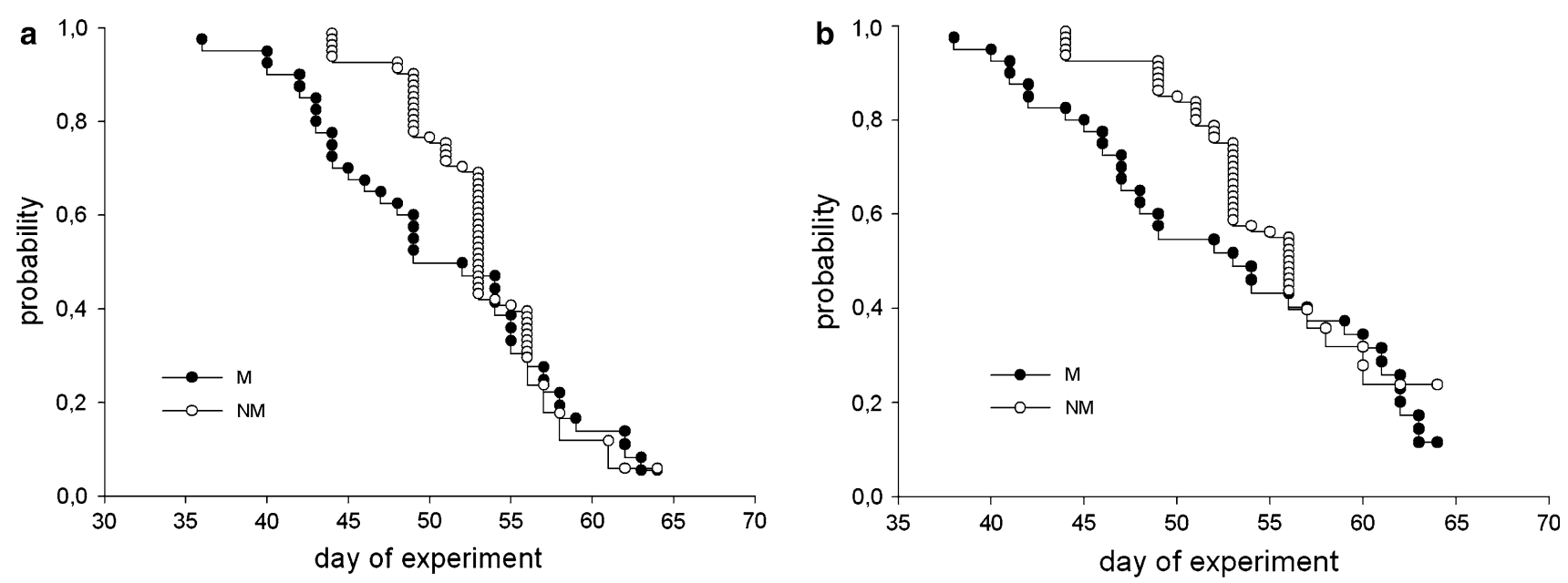

Fig. 5 Kaplan-Meier curves showing predicted probability of "no flowering" of A. arenosa plants originating from M and NM populations subjected to different $\mathrm{Zn}$ concentrations: a. $155 \mu \mathrm{M} \mathrm{Zn}^{2+}$ and b. $775 \mu \mathrm{M} \mathrm{Zn^{2+ }}$

experiment stress can be excluded as a factor influencing observed phenomena.

Differences in the onset of flowering between populations in control plants

It is accepted that flowering is controlled by four main pathways promoting flowering phase: photoperiodic, vernalization, autonomous, and hormonal (Zeevaart 2006). Autonomous and hormonal pathways are thought to be independent from environmental factors, but connected with plant development and age (e.g. Mouradov et al. 2002; Wang et al. 2012). Photoperiodic and vernalization pathways are controlled by environmental factors such as day length or temperature (e.g. Mouradov et al. 2002; Wang et al. 2012) and thus are likely to be involved in local adaptation in plants.

Numerous studies focused on intraspecific variation and ecotypes pointed out that different onset of flowering is likely to be the result of natural selection. This phenomenon is usually associated with the notion that only those plants whose life history traits (including the onset of flowering) "fits" the environment of a particular area will survive in the long-term (Briggs and Walters 2000). In our case $\mathrm{Zn}$ content in the soil was the most interesting factor that could potentially influence flowering patterns in investigated populations. In our study we used four different $\mathrm{M}$ and NM populations of A. arenosa. If early flowering was an important factor contributing to plant survival in Zn-rich polluted environment we should expect that plants from metallicolous (M) populations should differ from plants from non-metallicolous (NM) populations in terms of flowering onset due to the selection of well adopted genotypes. To answer this question we investigated differences in the onset of flowering between $\mathrm{M}$ and $\mathrm{NM}$ populations of $A$. arenosa in control plants.

Our results suggest that time to the onset of flowering is probably not a selected trait in M and NM populations of $A$. arenosa and that both types of populations do not differ in this aspect in controlled conditions. It also means that preexisting differences in the onset of flowering, present between populations and being an effect of local adaptation, had no impact on our observations.

Stimulation of the onset of flowering by low $\mathrm{Zn}$ concentrations

Many environmental factors can influence the onset of flowering (Bernier and Perilleux 2005) and plants are able to detect these environmental stimuli and react adjusting their development (Ausin et al. 2005; Yaish et al. 2011).

Different environmental factors such as light and temperature show predictable and repeatable pattern of variation during the year and have a major effect on flowering season in wild plants. There are also other factors, however, such as wind or nutrient content in the substrate that can influence the onset of flowering in different plant species. It seems that zinc, as a mineral nutrient, may play here a special role. Golcz and Seidler-Lozykowska (2009) investigated the content of mineral nutrients (including $\mathrm{Zn}$ ) in plants at different stages of development. They showed that the maximal amounts of zinc were accumulated during the onset of flowering, full flowering stage and during seed setting by three different plant species: Origanum majorana, Ocimium basilicum and Satureja hortensis. These results suggest that zinc may play a role in regulation of flowering. 
It seems that the impact of Zn on plant physiology can differ substantially between species or even between conspecific populations. It is widely known that $\mathrm{Zn}$ is an essential element which is indispensable for plants. On the other hand zinc deficiency (resulting from decreased $\mathrm{Zn}$ bioavailability in soil) is a widespread problem in many areas of the world. It is estimated that nearly $50 \%$ of the cereal-cultivated soils have $\mathrm{Zn}$ deficiency problem, causing decreased crop yields (Cakmak 2008). It is also believed that $\mathrm{Zn}$ deficiency is the most widespread micronutrient deficiency in crop plants (Ozturk et al. 2006; Cakmak et al. 1999; Cakmak 2008). At the opposite pole from soils with $\mathrm{Zn}$ deficit there are places where substrate is unusually rich in this metal. Some of these soils are so rich in $\mathrm{Zn}$ that excess of this nutrient becomes a major factor limiting plant growth (Ernst 2006) and only some plants were able to adapt to such extreme environments (e.g. Przedpelska and Wierzbicka 2007; Abratowska et al. 2012). It is highly probable that $\mathrm{Zn}$ metabolism and the impact of this metal on physiological processes could be different in plants from $\mathrm{Zn}$-poor and $\mathrm{Zn}$-rich soils.

To investigate plant response to $\mathrm{Zn}$ and expressed as changes in the onset of flowering also in this context we choose A. arenosa as the most suitable model species having (1) well developed strategies facilitating adaptation to different environments and (2) occurring in places with both low and excessively high content of zinc in the soil. It seemed to us that investigating plants from two different physiological phenotypes (adopted to low and high concentration of $\mathrm{Zn}$ in the soil), we will be able to show whether plant response to $\mathrm{Zn}$ manifested as differences in the onset of flowering were an effect of the local adaptation to Zn-rich or Zn-poor soils, or constitutes an universal, "constitutional" plant response exhibited by both physiological phenotypes present within the species.

It has been shown that flowering time in A. arenosa is regulated by temperature and day length (Nah and Chen 2010). It has been also evidenced that the species need about 60 days from germination to the onset of flowering (Przedpelska and Wierzbicka 2007; Nah and Chen 2010). Hitherto, however, there was no observations showing the impact of zinc on early flowering both in A. arenosa as well as in other plant species. This is surprising, especially when taking into account that zinc has a special place among heavy metals. On the one hand the metal is able to cause phytotoxic effects, on the other hand, however, it plays a key role in many different metabolic processes in plants (Mengel and Kirkby 2001; Nahed Abd El-Aziz and Balbaa 2007; Kabata-Pendias 2010).

We found that in each investigated population at least one non-toxic concentration of zinc in the growth medium caused significant stimulation of the onset of flowering. The lowest concentration applied $\left(155 \mu \mathrm{M} \mathrm{Zn^{2+ }}\right)$ caused significant acceleration of the onset of flowering in plants from all populations studied. The same phenomenon was observed when data from overall sample was taken into account in one analysis. Significant results of statistical test indicate that plants treated with $\mathrm{Zn}$ started to flower earlier than the control plants. It was also clear that differences existed not only between the control and treated plants, but also between treatments. The lowest applied $\mathrm{Zn}$ concentration $\left(155 \mu \mathrm{M} \mathrm{Zn^{2+ }}\right)$ stimulated the onset of flowering most efficiently. These results have shown that zinc present in the growth medium in low and non-toxic concentrations promote early flowering in A. arenosa. We have also shown that the effect of stimulation may depend on the $\mathrm{Zn}$ concentration applied. In our case the lowest $\mathrm{Zn}$ concentration had the strongest effect. Our previous experiments (see above) analyzing chlorophyll fluorescence and biomass accumulation have shown that the observed phenomenon cannot be interpreted as an effect of stress.

Our results suggest also that early flowering observed in $\mathrm{Zn}$ treated plants is an universal characteristic present within the species and is not influenced by the origin of plant material

Our previous studies (Przedpelska and Wierzbicka 2007) evidenced the presence of two physiological phenotypes present within A. arenosa: one inhabiting Zn-poor soils and the other one present in Zn-rich soils. These phenotypes were found to be different in terms of several morphological and physiological characteristics and were hypothesized to be a product of local adaptation to $\mathrm{Zn}$ polluted soils (Przedpelska and Wierzbicka 2007). In light of these findings, it was reasonable to assume that plants from these two phenotypes can differ in terms of their response to $\mathrm{Zn}$ treatment in the present experiment. Surprisingly, however, we did not evidenced any differences in plant response to applied $\mathrm{Zn}$ concentrations manifested as changes in the onset of flowering. Analyses carried out on the data collected from plants originating from $\mathbf{M}$ and NM populations showed that regardless the concentration applied (155 or $775 \mu \mathrm{M} \mathrm{Zn}^{2+}$ ) no significant differences in the onset of flowering were observed.

It seems therefore that regardless the origin of the material studied, plant response to applied Zn concentrations was the same. This finding seem to confirm our previous observations that $\mathrm{Zn}$-induced early flowering is not associated with particular phenotype well adopted to local environment (especially in terms of $\mathrm{Zn}$ excess in the substrate).

Explanation of the phenomena observed by us is difficult on the basis on contemporary knowledge on the regulation of flowering. Similar reaction-early floweringwas also observed by Wang et al. (2012) in A. thaliana in response to cadmium. They concluded that the phenomenon of early flowering was induced by up regulated 
expression of $\mathrm{CO}$ and $\mathrm{FT}$ genes that play a key role in photoperiodic pathway of flowering regulation. We should bear in mind, however, that $A$. thaliana is highly sensitive to cadmium and that observed stimulation of the onset of flowering might have been induced by stress. It cannot be confirmed at present whether the mechanism of early flowering described in A.thaliana in response to cadmium can be the same or at least similar in A. arenosa. Both metals have similar chemical properties: they have similar atomic radius, similar oxidation state in chemical compounds and share similar geochemical properties (Emsley 1991; Kabata-Pendias 2010) and both have been evidenced to interact similarly with different marcomolecules in plant cells (e.g. Przedpelska-Wasowicz et al. 2012; PrzedpelskaWasowicz and Wierzbicka 2011; Wierzbicka et al. 2007). Taking this into account, similar mechanism could be postulated for both phenomena. Highly similar genomes of both species (Clauss and Koch 2006) also seems to support this hypothesis. Surely, however, further research on gene expression in A. arenosa in response to $\mathrm{Zn}$ treatment is needed to elucidate the problem completely.

It seems that if response to low $\mathrm{Zn}$ concentrations is similar also in other plant species, particularly those of economic significance, some level of $\mathrm{Zn}$ surplus in fertilizers may induce early flowering if desired. This question requires also further research and confirmation.

\section{Conclusions}

Our research showed that increased $\mathrm{Zn}$ content in the growth medium caused increased $\mathrm{Zn}$ concentration in investigated plants and promoted the onset of flowering in A. arenosa. We evidenced also that applied Zn concentrations had no harmful effect on plants used in our experiments, and that stress can be excluded as a factor contributing to early onset of flowering in $\mathrm{Zn}$ treated plants. It seems that acceleration in the onset of flowering induced by $\mathrm{Zn}$ may depend on $\mathrm{Zn}$ concentration employed. Carrying out experiments on plants belonging to two different physiological phenotypes (adopted and non-adopted to high $\mathrm{Zn}$ content in the substrate) allowed us to confirm that $\mathrm{Zn}$-induced early flowering in A. arenosa is an universal plant response present within the species and is not a part of physiological adaptation to high $\mathrm{Zn}$ content in the environment.

Acknowledgments Authors would like to thank prof. M. Wierzbicka (Department of Biology, University of Warsaw) for her support and encouragement during experiments and D. Sakowski for his help in plant cultivation. Prof. E. Romanowska is acknowledged for making possible chemical analyses. We would like to thank anonymous reviewers for their suggestions and comments that significantly improved the manuscript.
Open Access This article is distributed under the terms of the Creative Commons Attribution License which permits any use, distribution, and reproduction in any medium, provided the original author(s) and the source are credited.

\section{References}

Abratowska A, Wasowicz P, Bednarek PT, Telka J, Wierzbicka M (2012) Morphological and genetic distinctiveness of the metallicolous and non-metallicolous populations of Armeria maritima s. L. (Plumbaginaceae) in Poland. Plant Biol 14:586-595

Andrews JR, Fryer MJ, Baker NR (1995) Characterization of chilling effects on photosynthetic performance of maize crops during early season growth using chlorophyll fluorescence. J Expt Bot 46:1195-1203

Ausin I, Alonso-Blanco C, Martinez-Zapater JM (2005) Environmental regulation of flowering. Int J Dev Biol 49:689-705

Bernier G, Perilleux C (2005) A physiological overview of the genetics of flowering time control. Plant Biotech J 31:3-16

Briggs D, Walters SM (2000) Plant variation and evolution. Cambridge University Press, Cambridge, p 174

Brun LA, Le Corft J, Maillet J (2003) Effects of elevated soil copper on phenology, growth and reproduction of five ruderal plant species. Environ Pollut 122:361-368

Cakmak I (2008) Enrichment of cereal grains with zinc: agronomic or genetic biofortification? Plant Soil 302:1-17

Cakmak I, Kalayci M, Ekiz H, Braund HJ, Kilinc Y, Yilmaz A (1999) Zinc deficiency as a practical problem in plant and human nutrition in Turkey: a NATO-science for stability project. Field Crop Res 60:175-188

Clauss M, Koch M (2006) Arabidopsis and its poorly known relatives. Trends Plant Sci 11:449-459

Emsley J (1991) The elements (Oxford Chemistry Guides). Clarendon Press, Oxford

Ernst WHO (2006) Evolution of metal tolerance in higher plants. For Snow Landsc Res 80:251-274

Golcz A, Seidler-Lozykowska K (2009) Content of microelements in raw materials of basil (Ocimum basilicum L.), savory (Satureja hortensis L.) and marjoram (Origanum majorana L.) collected in the different stages of plant development. Nauka Przyroda Technologie 3:\#74

Kabata-Pendias A (2010) Trace elements in soils and plants. CRC Press, Boca Raton

Kaplan EL, Meier P (1958) Nonparametric estimation from incomplete observations. J Am Stat Assoc 53:457-481

Kirkwood BR, Sterne JAC (2003) Essential medical statistics, 2nd edn. Blackwell Science, Oxford, p 272

Kitajima M, Butler WL (1975) Quenching of chlorophyll fluorescence and primary photochemistry in chloroplasts by dibromothymoquinone. Biochim Biophys Acta 376:105-115

Koch MA, Haubold B, Mitchell-Olds T (2000) Comparative evolutionary analysis of chalcone synthase and alcohol dehydrogenase loci in Arabidopsis, Arabis, and related genera (Brassicaceae). Mol Biol Evol 17:1483-1498

Malle KG (1992) Zink in der Umwelt. Acta Hydrochim Hydrobiol 20:196-204

Mallick N, Mohn FH (2003) Use of chlorophyll fluorescence in metalstress research: a case study with the green microalga Scenedesmus. Ecotoxicol Environ Safety 55:64-69

Maxwell K, Johnson GN (2000) Chlorophyll fluorescence-a practical guide. J Expt Bot 51:659-668

Mengel K, Kirkby EA (2001) Principles of plant nutrition. Kluwer, Dordrecht

Mouradov A, Cremer F, Coupland G (2002) Control of flowering time: interacting pathways as a basis for diversity. Plant Cell 14:S111-S130 
Nah G, Chen ZJ (2010) Tandem duplication of the FLC locus and the origin of a new gene in Arabidopsis related species and their functional implications in allopolyploids. New Phytol 186:228-238

Nahed Abd El-Aziz G, Balbaa LK (2007) Influence of tyrosine and zinc on growth, flowering and chemical constituents of Salvia farinacea plants. J Appl Sci Res 3:1479-1489

Neil K, Wu J (2006) Effects of urbanization on plant flowering phenology: a review. Urban Ecosyst 9:243-257

Ozturk L, Yazici MA, Yucel C, Torun A, Cekic C, Bagci A, Ozkan H, Braun HJ, Sayers Z, Cakmak I (2006) Concentration and localization of zinc during seed development and germination in wheat. Physiol Plantarum 128:144-152

Przedpelska E, Wierzbicka M (2007) Arabidopsis arenosa (Brassicaceae) from a lead-zinc waste heap in southern Poland-a plant with high tolerance to heavy metals. Plant Soil 299:43-53

Przedpelska-Wasowicz E, Wierzbicka M (2011) Gating of aquaporins by heavy metals in Allium cepa L. epidermal cells. Protoplasma 248:663-671

Przedpelska-Wasowicz E, Polatajko A, Wierzbicka M (2012) The influence of cadmium stress on the content of mineral nutrients and metal-binding proteins in Arabidopsis halleri. Water Air Soil Pollut. doi:10.1007/s11270-012-1292-4

Putterill J, Robson F, Lee K, Simon R, Coupland G (1995) The CONSTANS gene of arabidopsis promotes flowering and encodes a protein showing similarities to zinc finger transcription factors. Cell 80:847-857

Robson F, Costa MMR, Hepworth SR, Vizir I, Pineiro M, Reeves PH, Putterill J, Coupland G (2001) Functional importance of conserved domains in the flowering-time gene CONSTANS demonstrated by analysis of mutant alleles and transgenic plants. Plant J 28:619-663

Roux F, Touzet P, Cuguen J, Le Corre V (2006) How to be early flowering: an evolutionary perspective. Trends Plant Sci 11: $375-381$
Schreiber U, Bilger W, Neubauer C (1994) Chlorophyll fluorescence as a non-intrusive indicator for rapid assessment of in vivo photosynthesis. In: Schulze ED, Caldwell MM (eds) Ecophysiology of photosynthesis. Ecological Studies, vol 100, Springer, Berlin, pp 49-70

Strebeyko P (1967) Introduction to plant physiology. PWRiL, Warsaw

Turnbull C (2011) Long-distance regulation of flowering time. J Exp Bot 62:4399-4413

Wada KC, Takeno K (2010) Stress-induced flowering. Plant Signal Behav 5:944-947

Waldhoff D, Furch B, Junk WJ (2002) Fluorescence parameters, chlorophyll concentration, and anatomical features as indicators for flood adaptation of an abundant tree species in central Amazonia: Symmeriapaniculata. Environ Exp Bot 48:225-235

Wang WY, Xu J, Liu XJ, Yu Y, Ge Q (2012) Cadmium induces early flowering in Arabidopsis. Biol Plantarum 56:117-120

Wierzbicka M, Panufnik D (1998) The adaptation of Silene vulgaris to growth on a calamine waste heap (S. Poland). Environ Pollut 101:415-426

Wierzbicka MH, Przedpelska E, Ruzik R, Ouerdane L, Polec-Pawlak K, Jarosz M, Szpunar J, Szakiel A (2007) Comparison of the toxicity and distribution of cadmium and lead in plant cells. Protoplasma 231:99-111

Yaish MW, Colasanti J, Rothstein SJ (2011) The role of epigenetic processes in controlling flowering time in plants exposed to stress. J Expt Bot 62:3727-3735

Zalecka R, Wierzbicka M (2002) The adaptation of Dianthus carthusianorum L. (Caryophyllaceae) to growth on a zinc-lead heap in southern Poland. Plant Soil 246:249-257

Zeevaart JAD (2006) Florigen coming of age after 70 years. Plant Cell 18:1783-1789 